\section{MARIA HELENA}

PRADO DE MELLO

JORGE é professora da

Faculdade de Saúde

Pública da USP.

\section{JOÃO YUNES}

é professor titular da

Faculdade de Saúde

Pública da USP.

\title{
Violência e saúde
}

\section{no Brasil}

\author{
MARIA HELENA PRADO DE MELLO JORGE \\ JOÃO YUNES
}

\section{PRELIMINARES}

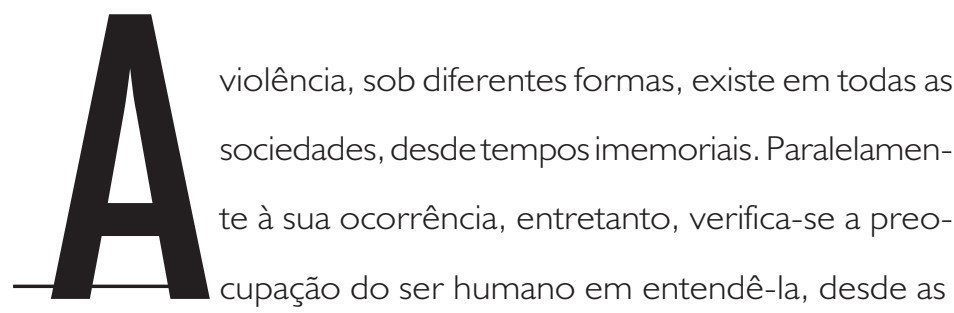

suas origens, para, dessa forma, combatê-la, atenuá-la, preveni-la.

Embora não se constitua em problema específico dessa área, a violência interessa ao setor saúde na medida em que "representa um risco para a realização do processo vital humano pois ameaça a vida, altera a saúde, produz enfermidade e provoca a morte, como realidade ou como possibilidade" (Agudelo, 1990). É, portanto, sob essa perspectiva que o setor saúde estuda a violência, medindo seu impacto sobre ela, através da violência que lesa e da violência que mata.

Esse conceito - internacional - é dado pela Organização Mundial da Saúde (OMS, 1995) e engloba todos os tipos de agravos acidentais e intencionais, vale dizer, os acidentes de todos os tipos e as violências propriamente ditas - auto e heteroconsumadas. Esses agravos, denominados "causas externas", mantidas as 
suas especificidades, devem ser estudados em conjunto, até porque, não raras vezes, apresentam limites tênues entre si, não sendo possível distinguir, com nitidez, a origem dos efeitos com que se apresentam sobre as pessoas. Sua complexidade, portanto, torna difícil classificar, com precisão, atos ou fatos acidentais e intencionais.

Os acidentes existem desde a época em que o homem enfrentava os grandes perigos de um ambiente hostil e, para sobreviver a inundações, tempestades, incêndios e ataques de animais, expunha-se ao risco de morrer.

A violência existia também em relação ao próprio semeIhante: o homem lutava contra o homem para defender a honra, a propriedade, para atingir o poder. $\bigcirc$ Antigo Testamento relata a morte de Abel por Caim (Genesis 4.8) e outros tantos casos aparecem desde então. As mortes dos Césares, pelos Césares, são outro exemplo de homicídios na história. Na Idade Média, as perseguições ditas religiosas, da Inquisição, mataram um semnúmero de pessoas. São célebres, também, os homicídios do rei Duncan, por Macbeth, para se apoderar do trono da Escócia; e dos filhos de Medéia, pela própria mãe, que os apunhalou para se vingar de Jasão.

O suicídio tem, também, história tão antiga quanto a da humanidade. O Evangelho de São Matheus relata o caso de Judas que, "tendo vendido e crucificado Jesus, enforcou-se". Na Grécia e Roma antiga eram numerosos os casos de suicídio. Aos tempos da decadência, os indivíduos, esgotados pela corrupção e excesso de prazeres, acabavam buscando, na morte, o remédio contra o tédio da vida. Os suicídios, por amor, por vingança, por imitação, multiplicaram-se na vida real e inspiraram a literatura e as artes. Shakespeare, Goethe e Dante mostram, em suas obras, heróis suicidas (Mello Jorge e Laurenti, 1997). Mais tarde, são os próprios escritores que se matam: Antero de Quental, Camilo, Hemingway e, entre nós, Raul Pompeia e Pedro Nava. 
Embora possa parecer paradoxal, à medida que foi aumentando o conhecimento científico - que possibilitou o desenvolvimento tecnológico em várias áreas - foi crescendo também a diversidade de tipos de causas externas. Os envenenamentos, que até o século XIX eram quase que exclusivamente por produtos naturais, passaram a ocorrer por novos produtos químicos: dióxido de enxofre, em 1930, na Bélgica; agente laranja, na Itália, em 1976; Bophal, na Índia, em 1984; césio, no Brasil, no final dos anos 80 .

A máquina a vapor e sua aplicação ao transporte ferroviário provocaram vários tipos de acidentes a partir do século XIX; o início do século XX viu o surgimento crescente dos acidentes de trânsito por veículos automotores. O primeiro acidente de trânsito, no Brasil, ocorreu em 1898, quando Olavo Bilac, na Estrada Velha da Tijuca, dirigia o carro de José do Patrocínio. Cantado também na prosa de Monteiro Lobato, Zélia Gattai e Albert Camus, foi, este último, anos mais tarde, vítima também de morte violenta por acidente de trânsito.

No ano de 1945 , a população mundial assistiu ao desastre da bomba atômica e, no final da década de 50, surgiu a possibilidade dos acidentes causados pelos veículos espaciais. As guerras química e bacteriológica aparecem como possibilidade não remota neste início do século XXI. Certamente, esta escalada não se esgota aqui, pois outros tipos de avanços tecnológicos deverão possibilitar a ocorrência de novos tipos de violência (Mello Jorge e Laurenti, 1997).

Em razão da importância desse quadro, o interesse de organizações internacionais pelo assunto vem, também, aumentando. Em 1955, quando da realização da VIII Assembléia Mundial da Saúde, em Genebra, foi proposto que a luta contra os acidentes fosse considerada um problema de saúde pública (Puffer e Serrano, 1973). Seis anos mais tarde, a Organização Mundial da Saúde escolheu como tema do ano "Acidentes e sua Prevenção", referindo-se à "necessidade de uma ação pronta de combate a esse flagelo" (Candeau, 1961). Em 1991, o tema do ano foi “Desastres não se fazem anunciar: é melhor prevenir do que remediar" (Nakagima, 1991); dois anos após, o então diretor da OMS chamava a atenção para o fato de que "a vida é frágil, previna a violência e a negligência" (OMS, 1993).

No Brasil, o assunto vem ocupando, de longa data, as manchetes dos jornais, bem como tem sido objeto de discussões, projetos e algumas tentativas de intervenção.

\section{COMO A VIOLÊNCIA AFETA 0 SETOR SAÚdE}

Embora se tenha claro que a área da saúde não participa da sua gênese, em outras palavras, não a cria, não a incrementa nem a desenvolve, é exatamente sobre esse setor que vai recair o maior ônus da violência. As causas externas se constituem hoje, em um indiscutível problema de saúde pública, com efeitos importantes sobre a mortalidade e sobre a morbidade da população.

\section{Efeitos sobre a mortalidade}

Do ponto de vista da violência levando à morte, informações trazidas por vários estudos mostram sua ocorrência em números elevados e crescentes. Sabe-se que morrem, hoje, no Brasil, cerca de 120.000 pessoas por ano, em decorrência de causas violentas (MS, SIM, 2001). Essas causas constituem-se no segundo grupo de causas de morte, representando cerca de $15 \%$ do total de óbitos no país, perdendo somente para as doenças do aparelho circulatório. Medidas em relação à população, verificam-se, em 1977 e em 1997, respectivamente, taxas de 50 e 75 por 100 mil habitantes, o que evidencia um crescimento de cerca de $50 \%$ nos últimos vinte anos.

Esses valores, além de representarem indicadores absolutamente negativos em relação à saúde de sua população, emprestam ao Brasil o título de quase campeão em mortes por causas violentas. Acresce que, 
em grande número de países, como resultado de medidas específicas postas em prática pelos governos, as taxas estão em queda. É possível ver, por exemplo, que, no Canadá, seus valores declinaram $28 \%$ entre 1980 e 1995, nos Estados Unidos, 22\% entre 1980 e 1997 e, no México, 39\% entre 1990 e 1995 . No Brasil, os dados experimentaram aumentos até 1997 e os de 1998 e 1999 parecem evidenciar um pequeno declínio, sendo, entretanto, precoce afirmar que isso representa, efetivamente, uma diminuição da violência entre nós.

Em largos traços, é possível mostrar também que o perfil dessa mortalidade aponta para o modelo internacional, que dá maior vulnerabilidade ao sexo masculinoe à população jovem. As mortes decorrentes de violência, entre homens, correspondem a cerca de quatro vezes as ocorridas entre as mulheres. Esta sobremortalidade masculina tem sido explicada em razão, provavelmente, de uma maior exposição do homem aos riscos de acidentar-se e morrer (Yunes, 1993; Souza e Minayo, 1994).

Quanto às idades, as causas externas constituem-se na primeira causa de morte dos 5 aos 39 anos de idade, sendo que, em várias áreas do país, como o próprio Distrito Federal, já representam a primeira causa de óbito desde a idade de 1 ano (Mello Jorge e col., 1997). Verifica-se, assim, ser exatamente entre os adolescentes, jovens e adultos jovens - população no auge de sua fase produtiva - que as causas externas evidenciam sua maior ocorrência. Diversos autores têm se referido ao fato de que a juventude constitui-se em uma fase da vida em que seus habitantes são hígidos: adoecem pouco e morrem menos ainda (Mello Jorge, 1998). Entretanto, comportamentos de risco assumidos por esse segmento populacional levam a que eles estejam mais expostos à violência e, por via de conseqüiência, à morte.

Esse padrão de incidência já está sendo responsável por provocar um desbalanço no equilíbrio demográfico do país, nas idades jovens, além de colocar em sério risco os ganhos obtidos na esperança de vida do povo brasileiro. Alguns autores têm apon- tado para o número de anos de vida perdidos em razão da mortalidade precoce provocada pelas causas externas.

Quanto aos tipos de causas violentas, o padrão verificado no início dos anos 80 , em que havia nítido predomínio das mortes por acidentes de trânsito, foi substituído por um modelo mais perverso, mais temido e mais preocupante. Os homicídios passaram a assumir a fatia preponderante dentre as causas externas e representam, hoje, cerca de $35 \%$ do seu total no país. No estado de São Paulo essa proporção é de $43 \%$ e no município de São Paulo, 64\% (FSeade, 2001 e Proaim, 2001).

No Brasil, os acidentes de trânsito que, do ponto de vista de sua distribuição geográfica, ainda preponderam em algumas áreas do país, como por exemplo a Região Sul, vêm experimentando declínio (Figura 1), o que pode ser atribuído a importantes fatores, como maior fiscalização, menor velocidade, implantação de lombadas eletrônicas, uso de cinto de segurança, entre outros. O Código Brasileiro de Trânsito, promulgado em 1997 e com vigência a partir de 1998, trouxe respaldo efetivo a medidas que vêm sendo postas em prática há algum tempo. Aspectos importantes são representados, ainda, entretanto, pela ocorrência de atropelamentos - principalmente de crianças e idosos e, mais recentemente, em larga escala, pelos acidentes de motocicleta, visto que estes veículos passaram a ser usados não somente para o lazer, mas como instrumento de trabalho, principalmente em serviços de entregas rápidas (Mello Jorge e col., 2001). Nesse campo, destacam-se como fundamentais os aspectos educativos, na medida em que atravessar a rua com segurança é um problema de educação para o trânsito e o uso de equipamentos de segurança como o capacete, no caso dos acidentes de moto, está com certeza associado à ocorrência de acidentes menos graves. Vários estudos têm mostrado que a cabeça é a região mais freqüentemente atingida no caso de acidentes fatais (Andrade, 1998; Koizumi, 1985; Mello Jorge e col., 2001).

Com referência aos homicídios (que provocaram quase 43.000 mortes, no país, 
em 1999), as taxas são elevadas para a população como um todo, mas especialmente altas no sexo masculino, chegando a ser igual a dez vezes a apresentada pelas mulheres, e principalmente nos jovens. $\mathrm{O}$ Brasil, ao lado da Colômbia, El Salvador e Porto Rico, é apresentado por Yunes e Zubarew (1999) como um dos países de mais altas taxas por homicídios nos jovens, na região das Américas. A incidência crescente das mortes por homicídio está a requerer alguma atitude por parte das autoridades. Suas taxas, que ocupavam o terceiro lugar, entre as causas externas, no início dos anos 80, chegam ao primeiro posto no começo da década de 90. Essa tendência de crescimento, verificada em todas as macrorregiões (Figura 1) e unidades da Federação, não se caracteriza somente como um fenômeno urbano, como tem sido salientado, mas ocorre tanto nas capitais dos estados, como em áreas menos desenvolvidas. Ao se analisarem as taxas de mortalidade por homicídio no Brasil, verificam-se aumentos mais significativos, por exemplo, no Mato Grosso, Amapá e Bahia. Entretanto, é o estado do Rio de Janeiro que apresenta as taxas mais elevadas entre os homens (Mello Jorge e Gotlieb, 2000).

Os suicídios representam uma forma de violência autoconsumada e vêm se apresentando, ao longo do tempo, no país, com taxas mais ou menos estáveis. Entretanto, para algumas idades e em áreas específicas, suas taxas começam a elevar-se, como está ocorrendo, por exemplo, no Rio Grande do Sul, principalmente nas idades jovens. Esse panorama levanta o questionamento relativo a se saber em que medida a falta de perspectivas quanto ao futuro estaria contribuindo para a autodestruição dos jovens (Mello Jorge, 1998).

Com relação ao fluxo dos "Demais acidentes", onde estão enfeixados os casos não enquadrados nos grupos anteriores, chamam a atenção alguns aspectos:

- quedas em crianças - são causas que nem sempre levam à morte, mas representam importante causa de internação. São responsáveis, muitas vezes, por traumatismos de crânio que podem deixar seqüelas irreversíveis; quanto às quedas em adultos, são decorrentes, principalmente, de acidentes do trabalho, em que a construção civil parece representar a atividade mais crítica; - afogamentos, que têm como alvo principal, crianças e adolescentes;

- violência doméstica, principalmente representada pela violência contra a criança, a mulher e o idoso.

Na Tabela 1 podem ser vistas as taxas de mortalidade por causas externas segundo tipo no Brasil, nos últimos vinte anos.

\section{A violência que lesa: medindo as internações hospitalares}

Do ponto de vista da violência que lesa, entendida como aquela que exige algum tipo de atendimento médico, seu impacto no setor saúde pode ser analisado por meio do congestionamento das emergências, dos gastos com o paciente traumatizado e da importância das seqüelas e incapacidades.

Com relação ao problema das emergências, embora não haja dados globais para o país com enfoque epidemiológico, estudos específicos e a própria mídia têm mostrado a importância e a gravidade do problema. Quanto aos gastos com o paciente traumatizado, algumas observações são importantes.

As internações por lesões decorrentes de causas externas (feitas nos hospitais próprios ou conveniados com o SUS), no país, cerca de 600 mil a 700 mil por ano, representam aproximadamente $6 \%$ do total de hospitalizações. Os acidentes e violências, como causa de internação, embora não dêem conta do total de hospitalizações no país, permitem um desenho, próximo do real, relativamente à mortalidade mais grave - a que necessita de cuidados hospitalares - e podem ser bastante úteis para várias finalidades. O sexo masculino também prepondera em número de internações, sendo, entretanto, ultrapassado pelas mulheres na faixa de 65 anos e mais. Em razão de as fraturas serem também em maior 
FIGURA I

Taxas médias de mortalidade por acidentes de trânsito e por homicídios (por 100 mil hab.). Brasil e regiões, 1979- 1999
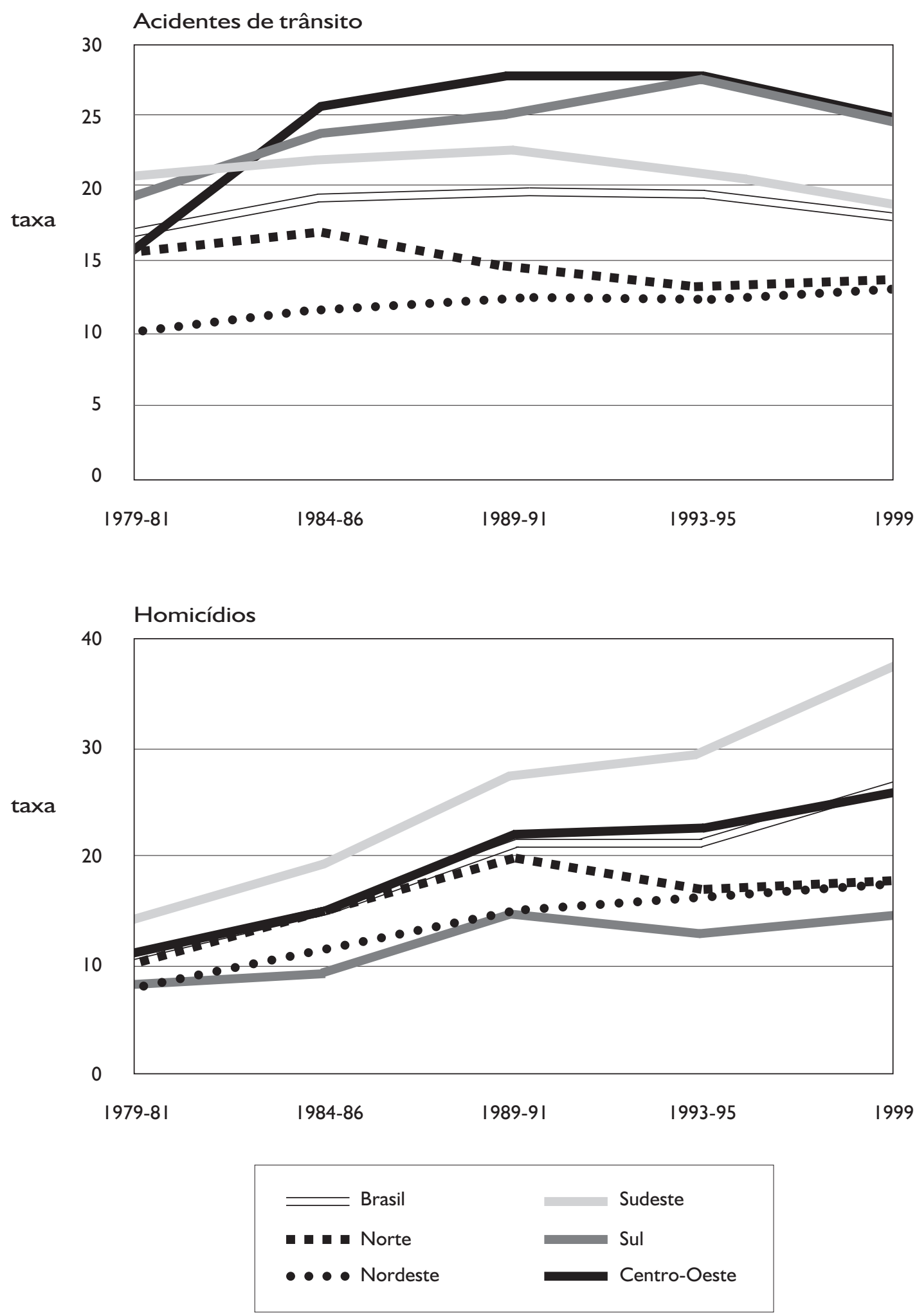
TABELA I

Mortalidade por causas externas segundo tipo (no e coeficiente por 100 mil hab.) - Brasil, 1977 a 1999

\begin{tabular}{|c|c|c|c|c|c|c|c|c|c|c|c|}
\hline \multirow[b]{2}{*}{ Ano } & \multicolumn{2}{|c|}{ Ac. trânsito } & \multicolumn{2}{|c|}{ Demais ac. } & \multicolumn{2}{|c|}{ Suicídios } & \multicolumn{2}{|c|}{ Homicídios } & \multirow{2}{*}{$\begin{array}{l}\text { Ign. } \\
\text { № }\end{array}$} & \multicolumn{2}{|c|}{ Total } \\
\hline & № & Coef. & № & Coef. & № & Coef. & № & Coef. & & № & Coef. \\
\hline 1977 & 17.795 & 16,1 & $|6.54|$ & 14,9 & 3.525 & 3,2 & 8.715 & 7,9 & 8.664 & 55.240 & 49,9 \\
\hline 1978 & 19.967 & 17,0 & 15.985 & $|4|$, & 3.255 & 2,9 & 9.146 & 8,1 & 11.330 & 59.683 & 52,7 \\
\hline 1979 & 20.825 & 18,0 & 16.234 & 14,0 & 3.490 & 3,0 & 11.194 & 9,7 & 13.510 & 65.253 & 56,3 \\
\hline 1980 & $|9.85|$ & 16,7 & 21.001 & 17,6 & 3.896 & 3,3 & 13.910 & 11,7 & 13.554 & 70.212 & 59,0 \\
\hline 1981 & 19.161 & 15,8 & 21.157 & 17,5 & 4.061 & 3,4 & 15.213 & 12,6 & $|2.24|$ & 71.833 & 59,5 \\
\hline 1982 & 20.755 & 16,8 & 20.436 & 16,6 & 3.917 & 3,2 & 15.550 & 12,6 & 12.802 & 73.460 & 59,5 \\
\hline 1983 & 20.077 & 15,9 & 24.781 & 19,7 & 4.586 & 3,6 & 17.408 & 13,8 & 11.226 & 78.008 & 61,9 \\
\hline 1984 & 21.942 & 17,7 & 23.407 & 18,2 & 4.433 & 3,5 & 19.767 & 15,4 & 12.837 & 82.386 & 64,1 \\
\hline 1985 & 24.298 & 18,5 & 23.898 & 18,2 & 4.256 & 3,2 & 19.747 & $|5|$, & 13.646 & 85.845 & 65,5 \\
\hline 1986 & 29.574 & 22,1 & 25.820 & 19,3 & 4.313 & 3,2 & 20.479 & 15,3 & 15.782 & 95.968 & 71,8 \\
\hline 1987 & 27.611 & 20,3 & 24.846 & 18,2 & 4.701 & 3,5 & 23.087 & 17,0 & 14.176 & 94.421 & 69,3 \\
\hline 1988 & 27.942 & 20,1 & 25.430 & 18.3 & 4.492 & 3,2 & 23.357 & 16,8 & 14.952 & 96.173 & 69,4 \\
\hline 1989 & 28.839 & 20,4 & 26.439 & 18,7 & 4.491 & 3,2 & 28.757 & 20,4 & 13.726 & 100.252 & 72.4 \\
\hline 1990 & 28.470 & 19,8 & 26.360 & 18,3 & 4.845 & 3,4 & 31.989 & 20,9 & 8.992 & 100.656 & 70,0 \\
\hline |99| & 27.866 & 19,0 & 27.623 & 18,0 & 5.186 & 3,5 & 30.750 & 20,9 & 10.578 & 102.023 & 69,5 \\
\hline 1992 & 26.627 & 17,9 & 25.941 & 17,4 & 5.259 & 3,5 & 28.374 & 19,1 & 12.743 & 98.944 & 66,5 \\
\hline 1993 & 27.289 & 18,0 & 26.464 & 17,5 & 5.555 & 3,7 & 30.610 & 20,2 & 13.833 & $103.75 \mid$ & 68,6 \\
\hline 1994 & 29.014 & 18,9 & 26.939 & 17,5 & 5.932 & 3,9 & 32.603 & 21,2 & 12.804 & 107.292 & 69,8 \\
\hline 1995 & 32.532 & 20,9 & 28.437 & 18,2 & 6.594 & 4,2 & 37.128 & 23,8 & 10.196 & | | 4.887 & 73,7 \\
\hline 1996 & 35.545 & 22,6 & 28.119 & 17,9 & 6.743 & 4,3 & 38.929 & 24,8 & 9.8290 & 119.156 & 75,9 \\
\hline 1997 & 35.756 & 22,4 & 27.181 & 17,0 & 6.923 & 4,3 & 40.531 & 25,4 & 9.159 & 119.550 & 74,9 \\
\hline 1998 & 30.994 & 19,2 & 24.564 & 15,2 & 6.985 & 4,3 & 41.940 & 25,9 & 13.117 & 117.600 & 72,7 \\
\hline 1999 & 29.569 & 18,0 & 27.085 & 16,5 & 6.530 & 4,0 & 42.947 & 26,2 & 10.769 & 116.900 & 71,3 \\
\hline
\end{tabular}

número, os dados sugerem tratar-se de acidentes do trabalho e de trânsito e, no sexo feminino, serem decorrentes de quedas. Quanto aos gastos, entretanto, correspondem a mais ou menos $8 \%$ do total despendido, o que evidencia que o paciente traumatizado é mais oneroso que aquele que se interna por causas naturais. Alguns trabalhos têm mostrado que o seu gasto/dia é $60 \%$ mais elevado que o daqueles internados em decorrência de doenças (Iunes, 1997).
Com referência à importância das seqüelas e incapacidades, não há dados gerais para o país. No ano de 1991, informações das Nações Unidas mostraram que, em cada mil habitantes, 17 apresentavam incapacidades, sem detalhar, entretanto, o tipo de incapacidade e o fato de ser ou não consequiente a trauma. Entre os danos produzidos no paciente, que exemplificam esta última situação, destacam-se, por exemplo, as lesões medulares traumáticas. Em 1997, foram atendidos, nos hospitais ligados ao 
SUS, 6.388 pacientes com fratura de coluna vertebral, sendo a taxa de internação mais elevada que nos anos anteriores. Quanto à localização da fratura, mais de $50 \%$ corresponderam aos segmentos cervical e dorsal, com comprometimento de medula, o que evidencia a provável ocorrência de paraplegia ou tetraplegia, mostrando a gravidade da situação (Laurenti e col., 1998).

Outros exemplos podem ainda ser dados: em 1997, na Rede Sarah de Doenças de Aparelho Locomotor (área de Brasília), do total de pacientes atendidos no ano 42,2\% eram vítimas de acidentes de trânsito, $24 \%$ de disparos de armas de fogo, $12,6 \%$ de mergulhos em águas rasas, $11,6 \%$ de quedas e 9,5\% de outros tipos de acidentes e violências (Ministério da Saúde, 2001).

A Associação de Assistência à Criança Defeituosa (AACD), em São Paulo, divulgando, recentemente, dados de seus pacientes, no ano 2000, revela que a maioria dos adolescentes atendidos - que há alguns anos apresentavam o perfil de serem vítimas de acidentes de trânsito - hoje é alvo de tentativas de homicídios ou de balas perdidas. No mesmo sentido, a Polícia Militar do estado de São Paulo, através de sua Caixa Beneficente, informa número não desprezível de policiais vitimados em ocorrências e, hoje, portadores de deficiências.

Também em todos esses casos, o adulto jovem apresenta-se como vítima importante, fato que evidencia, não somente um dano social, mas perdas importantes na vida, com qualidade, da população economicamente ativa.

Aspecto recente, mas bastante significativo para o setor saúde, e que vem se tornando quase comum - principalmente nos hospitais localizados nas periferias das grande cidades -, é representado pelos efeitos da violência sobre a estrutura e funcionamento dos serviços de saúde. Em São Paulo, a Secretaria de Saúde do Município tem encontrado dificuldades em preencher vagas de médicos e enfermeiros, na medida em que o atendimento de pacientes traumatizados tem gerado, nos profissionais de saúde responsáveis pelo mesmo, medo, ameaça e até mesmo danos físicos e psicológicos.

\section{Em busca dos fatores de risco}

Vários são os fatores de risco associados à violência, podendo-se destacar os que se seguem:

\section{1) Arma de fogo}

O aumento observado das taxas de homicídios nos últimos anos em vários países se deve ao uso de armas de fogo e, entre eles, destaca-se o Brasil. Para o ano de 1995, do total de homicídios ocorridos no país, $88,4 \%$ foram por arma de fogo (cerca de 41.000 casos). Esta proporção foi de $69,7 \%$ para os Estados Unidos e 4,5\% para o Japão. Falbo e col. (2001) encontraram, em um estudo realizado, em Recife, sobre homicídios em crianças e adolescentes, que a arma de fogo foi o instrumento utilizado em $97 \%$ dos óbitos.

Em 1997, o coeficiente mortalidade por arma de fogo no Brasil foi de 19 óbitos por 100 mil habitantes, enquanto em 1979 essa taxa havia sido 6 por 100 mil (havendo um aumento, portanto, de $220 \%$ nesse período).

Na Tabela 2 apresentam-se os coeficientes de mortalidade por arma de fogo para as capitais brasileiras. Observa-se, na tabela, que a média dos coeficientes das capitais, para o ano de 1997, foi de 24 óbitos por 100 mil habitantes, sendo Teresina a capital que apresentou o menor coeficiente $(4,7)$ e Recife o maior $(67,8)$.

Quando se estuda a mortalidade por homicídios causados por arma de fogo, observa-se, também aqui, uma predominância muito grande na população jovem do sexo masculino. Assim, para o grupo etário de 15 a 29 anos entre os homens, a capital com maior taxa de mortalidade por arma de fogo, em 1997, foi Recife (322), seguida por: Rio de Janeiro $(186,2)$, Vitória $(159,9)$, Salvador (144,5), Campo Grande $(114,5)$, Rio Branco $(114,5)$ e São Paulo $(103,7)$, todas medidas por 100 mil habitantes.

Ao se analisar a tendência da mortalidade por arma de fogo no município e no estado de São Paulo, observa-se que ela apresenta uma tendência de aumento, 
TABELA 2

Coeficientes de mortalidade por arma de fogo, capitais de estados - Brasil, 1997

\begin{tabular}{|c|c|}
\hline CAPITAL & $\begin{array}{l}\text { COEFICIENTE POR } \\
\text { I00 MIL HABITANTES }\end{array}$ \\
\hline Teresina & 4,7 \\
\hline Palmas* & 6,9 \\
\hline Florianópolis & 8,7 \\
\hline Belo Horizonte & 12,6 \\
\hline Fortaleza & 12,9 \\
\hline Belém & 13,5 \\
\hline Goiânia & 14,9 \\
\hline São Luís & 15,1 \\
\hline Curitiba & 16,9 \\
\hline Boa Vista & 17,9 \\
\hline Manaus & 19,0 \\
\hline Aracaju & 19,2 \\
\hline Porto Velho & 20,1 \\
\hline Natal & 20,2 \\
\hline João Pessoa & 20,5 \\
\hline Macapá & 21,4 \\
\hline Cuiabá & 21,6 \\
\hline Porto Alegre & 25,3 \\
\hline São Paulo & 25,7 \\
\hline Maceió & 25,9 \\
\hline Brasília & 26,1 \\
\hline Rio Branco & 29,3 \\
\hline Salvador & 31,8 \\
\hline Campo Grande & 33,1 \\
\hline Rio de Janeiro & 39,8 \\
\hline Vitória & 45,8 \\
\hline Recife & 67,8 \\
\hline Média das capitais & 24,0 \\
\hline
\end{tabular}

comportando-se como se fosse uma verdadeira epidemia. Este termo, emprestado do que ocorre com as causas infecciosas, vem sendo usado por epidemiologistas para expressar a maciça frequiência dos agravos decorrentes de causas externas, no Brasil (Mello Jorge e col., 1997; Yunes, 2001). É o que se observa na Tabela 3 , quando é apresentada a evolução da mortalidade por armas de fogo para a população do sexo masculino tanto no grupo etário de adolescentes ( 15 a 19 anos) quanto no de jovens (20 a 24 anos).

Fenômeno mais recente que se tem observado, na última década, é a maior mortalidade por arma de fogo em alguns municípios do interior, quando comparada com a de São Paulo (Tabela 4).

\section{2) Bebidas alcoólicas e drogas}

Um importante fator de risco para as várias formas de violência (acidentes de tráfico, homicídios e suicídios) é o consumo exagerado de bebida alcoólica. Nesse aspecto, verifica-se que o Brasil é o sexto produtor mundial de cerveja, tendo sido o consumo médio por pessoa por ano, em 1993, de 35 litros, portanto, maior que o do leite, que foi somente de 20 litros por pessoa/ano (Yunes, 2001)

$\mathrm{Na}$ área metropolitana de São Paulo, o aumento da violência tem sido atribuído ao consumo e ao tráfico de drogas, principalmente "crack"; este é, portanto, um fator associado à mortalidade por homicídios, inclusive a forma das chacinas, que também vêm aumentando assustadoramente. Segundo Adorno (1997), existem fortes suspeitas de que a motivação principal das chacinas seja a falta de pagamento de dívidas contraídas com o comércio e consumo de drogas.

O Disque Denúncia, criado pelo Instituto São Paulo Contra a Violência em parceria com a Secretaria de Segurança Pública do estado de São Paulo, mostra que 43,42\% das 23.537 denúncias registradas pela central telefônica no município de São Paulo, no período de 25/10/2000 a 31/8/ 2001 , deveram-se ao tráfico de drogas.

Relativamente ao álcool, na cidade de São Paulo, 12\% dos homicídios, em 1995, foram creditados a "brigas de bar" (Mingardi, 1996) e, segundo estudo feito a partir de laudos do Instituto Médico Legal, $50 \%$ das vítimas de homicídio apresentavam intoxicação alcoólica (Bastos e CarliniCotrim, 1998). 
TABELA 3

Coeficientes* de mortalidade por arma de fogo em adolescentes de 15 a 19 anos do sexo masculino e jovens de 20 a 24 anos, município de São Paulo e estado de São Paulo - 1979 -99

\begin{tabular}{lccccccccc}
\hline $\begin{array}{l}\text { I5 a 19 anos } \\
\text { REGIÃO }\end{array}$ & $1979-81$ & $1984-86$ & $1989-91$ & $1993-95$ & 1996 & 1997 & 1998 & 1999 \\
\hline $\begin{array}{l}\text { Município de } \\
\text { São Paulo }\end{array}$ & 10,5 & 49,4 & 62,0 & 80,4 & 85,3 & 84,0 & 98,0 & 135,0 \\
$\begin{array}{l}\text { Estado de } \\
\text { São Paulo }\end{array}$ & 8,1 & 26,9 & 37,8 & 44,1 & 50,8 & 51,1 & 63,1 & 85,1 \\
\hline $\begin{array}{l}20 \text { a } 24 \text { anos } \\
\text { REGIÃO }\end{array}$ & $1979-81$ & $1984-86$ & $1989-91$ & $1993-95$ & 1996 & 1997 & 1998 & 1999 \\
\hline $\begin{array}{l}\text { Munić́pio de } \\
\text { São Paulo }\end{array}$ & 13,4 & 47,3 & 68,4 & 111,2 & 125,6 & 129,8 & 145,0 & 190,8 \\
$\begin{array}{l}\text { Estado de } \\
\text { São Paulo }\end{array}$ & 12,9 & 33,8 & 49,6 & 65,3 & 81,2 & 87,4 & 95,9 & 119,2 \\
\hline * Coeficiente por 100 mil hab. & & & & & & Fonte: FSeade \\
\hline
\end{tabular}

\section{TABELA 4}

Coeficientes* de mortalidade por arma de fogo em adolescentes de 15 a 19 anos do sexo masculino e jovens de 20 a 24 anos nos municípios de São Paulo, Campinas e São José dos Campos - 1979-99

\begin{tabular}{|c|c|c|c|c|c|c|c|c|}
\hline \multicolumn{9}{|l|}{15 a 19 anos } \\
\hline MUNICÍPIOS & $|979-8|$ & $1984-86$ & |989-9| & $1993-95$ & 1996 & 1997 & 1998 & 1999 \\
\hline São Paulo & 10,5 & 49,4 & 62,0 & 80,4 & 85,3 & 84,0 & 98,0 & 135,0 \\
\hline Campinas & 15,8 & 38,0 & 44,4 & 84,1 & 74,9 & 105,9 & 155,6 & 213,3 \\
\hline São José dos Campos & 36,4 & 42,3 & 51,6 & 131,3 & 168,7 & 144,7 & 193,0 & 217,0 \\
\hline \multicolumn{9}{|l|}{20 a 24 anos } \\
\hline MUNICÍPIOS & |979-8| & 1984-86 & |989-9| & $1993-95$ & 1996 & 1997 & 1998 & 1999 \\
\hline São Paulo & 13,4 & 47,3 & 68,4 & 111,2 & 125,6 & 129,8 & 145,0 & 190,8 \\
\hline Campinas & 19,8 & 50,9 & 63,0 & 97,6 & 110,2 & 172,3 & 176,0 & 283,4 \\
\hline São José dos Campos & 37,6 & 53,5 & 69,1 & 155,2 & 240,9 & 184,3 & 327,9 & 239,5 \\
\hline \multicolumn{7}{|c|}{ * Coeficiente por 100.000 hab. } & \multicolumn{2}{|c|}{ Fonte: FSeade } \\
\hline
\end{tabular}

\section{3) Iniquidade social}

A inter-relação entre pobreza e violência é de difícil interpretação, uma vez que são múltiplos os fatores que se associam à pobreza. A população mais pobre, além de ter baixo ingresso, sofre de múltiplas privações que podem contribuir como fatores favoráveis à violência (Yunes, 2001). Segundo Baker e col. (1992), nos Estados Uni- dos, as taxas de homicídios foram duas vezes e meia maiores na população de nível socioeconômico baixo do que no alto. A esse problema adiciona-se a questão social, onde a violência, naquele país, ocorre principalmente na população de raça negra.

O desemprego tem sido apontado, também, como fator contribuinte para a prática da violência. $O$ aumento do desemprego, segundo Quadros (1), atinge de forma mais
W. Quadros, Artigo publicado em Folha de S. Paulo, cad. B-11, 7/10/01. 
acentuada, exatamente, as camadas da população que tiveram maior queda de renda, o que faz da redução de oferta de trabalho a principal causa de concentração de renda do país. Aliás, esta aumentou ainda mais, recentemente, pois, em 1992, o grupo mais rico da população ficou com $41,1 \%$ do total da renda do país, enquanto, em 1998, essa proporção aumentou para 45,1\%. Esse autor, ao analisar o desemprego segundo faixa etária, constatou que os jovens têm sido os mais prejudicados, uma vez que $54 \%$ dos desocupados têm até 24 anos de idade e metade deles encontra-se na faixa de 15 a 19 anos. Com referência à proporção de desempregados na população economicamente ativa, segundo áreas do município de São Paulo, em 1999, é possível constatar uma relação inversa, quando comparada à taxa de homicídios. Na Região Sudeste 1 , onde a proporção de desempregados foi de $8,3 \%$ da população economicamente ativa, a taxa de homicídios foi de 18,2 óbitos por 100 mil habitantes, enquanto na Região Leste 1, a uma maior proporção de desempregados $(12,1 \%)$ correspondeu uma maior taxa de mortalidade por homicídio (63,2 por 100 mil habitantes).

A mesma inter-relação pôde ser observada para as áreas periféricas do município de São Paulo, para o mesmo ano. Na área periférica Leste 2, a proporção de desemprego foi de $16,5 \%$ da população economicamente ativa, correspondendo a uma taxa de homicídio de 33,5 óbitos por 100 mil habitantes, enquanto, para a área periférica Sul 1, onde a taxa de desemprego foi maior $(21,2 \%)$, também a taxa de homicídio foi superior, apresentando um coeficiente de 82,3 por 100 mil habitantes.

Para Quadros, a elevada taxa de desocupação juvenil representa, ao lado da morte por causas violentas, um dos principais indicadores da gravidade social que atinge as famílias pobres. O alto ingresso econômico para poucos e o baixo ingresso para muitos podem conduzir os comportamentos violentos nos subgrupos de população mais excluídos. Embora se reconheça não haver uma relação direta entre pobreza e violência (Zaluar, 1986), fica evidente que a erradicação da pobreza e das desigualdades sociais deve ser parte integral de qualquer programa na luta contra a violência.

\section{4) Anacronismo das leis e impunidade da justiça e da polícia}

A impunidade do sistema judicial e a pouca credibilidade da polícia têm sido identificadas como mais um fator de risco que se agrega aos anteriormente mencionados, fazendo com que cresça, cada vez mais, o sentimento de que a justiça deva ser exercida pelas próprias mãos do cidadão. Isto faz pensar em que pode parecer que o exercício da violência esteja em processo de legitimação. Como apenas uma pequena parcela dos agressores identificados sofre sanções, esse fato pode vir a favorecer ou estimular o comportamento agressivo dos indivíduos.

\section{5) Meios de comunicação}

O aumento acelerado da divulgação da violência por parte dos meios de comunicação contribui, sem dúvida, para estimular e banalizar o fenômeno da violência. A televisão, o cinema e os jogos de vídeo promovem o comportamento e a opção pela violência, apresentada como forma de diversão e de busca de emoções e, muitas vezes, como proposta de solução para o que não está bem. Se um comercial de vinte segundos é capaz de manipular o gosto e o comportamento da população, com maior razão, horas e horas de violência televisionada podem vir a deformar a mente infantil. Existem muitos exemplos de comportamentos violentos moldados a comportamentos observados tanto no cinema como na televisão.

Em nosso meio, é muito comum observarem-se crianças que gastam mais tempo em jogos eletrônicos ou diante da televisão do que em horas na escola ou em tarefas escolares. Essa situação predispõe a uma maior disposição para optar pela violência.

Ainda que possa haver controvérsia sobre o papel dos meios de comunicação, é 
importante esclarecer que o aumento da oscilação da violência na mídia representa um fator de risco, cujo efeito é somado aos mencionados anteriormente. Os meios de comunicação não são, evidentemente, a única causa de motivação da violência mas, com certeza, o aumento desproporcionado de divulgação da violência na mídia pode contribuir para incrementá-la (Yunes, 2001).

\section{6) Outros}

Falbo e col. (2001), no trabalho citado, encontraram que o uso de drogas ilícitas e o registro de antecedentes policiais foram identificados como fatores de risco e que um maior grau de escolaridade, a prática religiosa e a presença do pai na casa foram identificados como fatores protetores para a violência. No contexto da prevenção da violência, a educação representa um valor muito importante na eqüidade social. Estar na escola não somente conduz a uma melhor educação, mas também a uma maior socialização, favorecendo a criança a se ajustar nos moldes de comportamento aceitáveis pela sociedade. Além do papel educador da escola, ela também tem o efeito de levar as crianças e os jovens a aceitarem a disciplina e o respeito pelas normas, bem como de representar um importante fator protetor e de socialização (Yunes, 2001). Merece ser registrada a iniciativa conjunta da Unesco e do governo do estado do Rio de Janeiro no projeto Escola da Paz. Neste, cerca de 250 escolas públicas do Rio de Janeiro estão abrindo suas portas no fim de semana, com o objetivo de manter a criança e o jovem na escola e evitar que eles se envolvam em atividades violentas. Atualmente, cerca de 750 jovens, por dia, freqüentam essas escolas exercendo atividades em quadras de esporte e em palcos armados em salas de aula. A proposta do programa é abrir espaços públicos para a comunidade, principalmente em áreas de maior vulnerabilidade social. O projeto aproveita talentos e a produção cultural das próprias comunidades. Essa programaçãoé organizada pelos próprios estudantes, que funcionam como monitores e recebem uma bolsa mensal e são os respon- sáveis por atrair vizinhos, parentes e amigos para participar de atividades (2).

\section{O PAPEL DO SETOR SAÚDE NO ENCAMINHAMENTO DO PROBLEMA}

O mapeamento da morbimortalidade por causas externas no Brasil mostra uma situação de epidemia, conforme referido, principalmente com relação aos acidentes de trânsito e homicídios - uma verdadeira guerra urbana - e clama pela implantação e pelo desenvolvimento de medidas tendentes a reverter esse quadro. Nesse sentido, é de se ressaltar documento importante elaborado por grupo de técnicos do Ministério da Saúde e profissionais convidados Política Nacional de Redução da Morbimortalidade por Acidentes e Violências - já aprovado em todos os níveis hierárquicos e assinado pelo ministro da Saúde (Ministério da Saúde, 2001). Esse documento, partindo do princípio de que os atos de violência são, em maior ou menor grau, previsíveis e preveníveis, estabelece e define diretrizes e níveis de atuação para o setor saúde, como também identifica responsabilidades institucionais para outros setores que intervêm no processo.

A partir de princípios básicos que a norteiam, a Política estabelece as seguintes diretrizes, que deverão orientar a definição dos instrumentos operacionais representados por planos, programas, projetos e atividades:

1) adoção de comportamentos e de ambientes seguros e saudáveis;

2) monitorização da ocorrência de acidentes e de violências;

3 ) sistematização, ampliação e consolidação do atendimento pré-hospitalar;

4) promoção de assistência interdisciplinar e intersetorial às vítimas de acidentes e de violências;

5) estruturação e consolidação do atendimento voltado à recuperação e à reabilitação;

6) capacitação de recursos humanos;

7) apoio ao desenvolvimento de estudos e pesquisas.
2 Jornal $O$ Estado de S. Paulo fls. A-13, 7/10/2001 
A partir do fato de que insistir na prevenção primária faz aumentar o impacto e a abrangência na proteção da população e baixar o custo de atendimento às vítimas, prevê também uma articulação intersetorial, buscando, inclusive, o en- gajamento de toda a sociedade. A reversão do quadro da morbimortalidade, baseada, fundamentalmente, na sua prevenção, é prioritária no Brasil, razão pela qual deve passar a fazer parte da agenda de todos nós.

\section{BIBLIOGRAFIA}

ADORNO, S. "La Criminalidad Violenta Urbana en Brasil: Tendencias y Caracteristicas", apresentado na reunião sobre El Desafio de la Violência Criminal Urbana, promovida pelo BID. Rio de Janeiro, 20-4/3/97.

AgUDELO, S. F. "La Violencia: un Problema de Salud Pública que se Agrava en la Región", in Bol. Epidemiol., OPS, 11, 1990, pp. 1-7.

ANDRADE, S. M. Acidentes de Trânsito em Londrina, PR. Tese de Doutorado. São Paulo, Faculdade de Saúde Pública da USP, 1998.

BAKER, R. S.; 0’NEILL, B. 0.; GINSBURG, M. J.; LI, G. The Injury Fact Book. New York, Oxford University Press, 1992.

BASTOS e CARLINI-COTRIM. “0 Consumo de Substâncias Psico-ativas entre Jovens Brasileiros: Dados, Danos e Algumas Propostas", in CNPD. Jovens Acontecendo na Trilha das Políticas Públicas. Brasília, 1998.

CANDEAU, M. “Del Fatalismo a la Investigación Cientifica”, in Salud Mundial, mai.-abr./1961.

FALBO, G. H. ; BUZZETTI, R.; CATTANEO, A. A. "Homicide in Children and Adolescents: a Case-control study in Recife, Brazil", in Bulletin of the World Health Organization, 79(1), Geneve, 2001, pp. 1-7.

IUNES, R. F. "Impacto Econômico das Causas Externas no Brasil: um Esforço de Mensuração”, in Rev. Saúde Pública, 31 (supl. 4), 1997, pp. 38-46.

KOIZUMI, M. S. "Acidentes de Motocicleta no Município de São Paulo (Brasil). 1. Caracterização do Acidente e da Vítima e 2. Análise da Mortalidade", in Revista de Saúde Pública, v.19(5), pp. 475-89 e v.19(6), pp. 543-55, 1985. LAURENTI, R. e col. "Hospitalizações por Fraturas da Coluna Vertebral". Congresso Internacional de Prevenção do Trauma, 1998

MELLO JORGE, M. H. P. e col. "Acidentes de Moto no Final do Segundo Milênio: Estudo de Pacientes Internados no Município de São Paulo", in Revista da Abramet, jan.fev./2001.

MELLO JORGE, M. H. P.; GAWRYSZEWSKI, V. P. e LATORRE, M. R. D. 0. "Análise dos Dados de Mortalidade", in Rev. Saúde Pública, 31 (supl. 4), 1997, pp. 5-25.

MELLO JORGE, M. H. P. e LAURENTI, R. Apresentação, in "Acidentes e Violência no Brasil". Rev. Saúde Pública, 31 (4), Suplemento, 1997.

MELLO JORGE, M. H. P. e col. "Análise dos Dados de Mortalidade". "Acidentes e Violências no Brasil", in Rev. Saúde Pública, 31 (4), Suplemento, 1997.

MELLO JORGE, M. H. P. e GOTLIEB, S. L. D. As Condições de Saúde no Brasil: Retrospecto de 1979 a 1995. Rio de Janeiro, Fiocruz, 2000.

MELLO JORGE, M. H. P. "Como Morrem os Nossos Jovens", in CNPD, Jovens Acontecendo na Trilha das Políticas Públicas. Brasília, 1998.

MINGARDI, G. e col. "A Violência Urbana na Zona Sul de São Paulo: um Estudo sobre o Homicídio e a Geografia do Crime na Região Urbana de São Paulo", 1996. Relatório apresentado à Secretaria da Segurança Pública do Estado de São Paulo. 
MINISTÉRIO DA SAÚDE. "Política Nacional de Redução da Morbimortalidade por Acidentes e Violências". Portaria MS/ GM № 737 de 16/5/01, Brasilia, 2001.

MINISTÉRIO DA SAÚDE. "Sistema de Informações sobre Mortalidade". Brasília, 2001 (CD-ROM).

NAKAGIMA, H. Desastres não se Fazem Anunciar, É Melhor Prevenir do que Remediar; Dia Mundial da Saúde, 1991", in Saúde Mundo mar./1991.

OMS - Organização Mundial da Saúde. "Report of the Second Global Liaison Meeting on Accident and Injury,

1986", apud Organización Panamericana de la Salud. Las Condiciones de Salud en las Americas. Washington, 1993, v.1 (Publicación Cientifica no 549).

PUFFER, R. R. e SERRANO, C. V. Características de la Mortalidad em la Niñez. Washington D.C., OPS, 1973.

(Publicación Cientifica no 262 ).

SOUZA, E. R. e MINAYO, M. C. S. "0 Impacto da Violência Social na Saúde Pública do Brasil: Década de 80". Rio de Janeiro, Claves, 1994 (mimeo.).

YUNES, J. e ZUBAREW, T. "Mortalidad por Causas Violentas en Adolescentes y Jovens: un Desafio para la Región de las Americas", in Rev. Brasileira de Epidemiologia, v. 2 (3), 1999.

YUNES, J. "Mortalidad por Causas Violentas en la Región de las Americas", in Bol. Ofic. Sanit. Panam., 114, 1993, pp. 303-15.

. "Epidemiologia da Violência", in M. C. Oliveira, Demografia da Exclusão Social: Temas e Abordagens. Campinas, 2001. 